\section{Mt Graham Observatory}

SIR-I should like to clarify the status of the Mt Graham Observatory proposal (Nature 334, 188 \& 645 and 335, 755; 1988). The site has been proposed by the University of Arizona (UA) as the location for future astronomical instrumentation. Legislation authorizing the establishment of a scientific research area, including astronomical facilities, was passed by the United States Congress on 20 October 1988.

The observatory proposal has been the subject of two environmental studies, neither of which identified any major effect except possibly on the endangered Mt Graham red squirrel. Two subsequent analyses by the US Forest Service, using recent survey data and computer models, have shown no significant effect on this possible subspecies; according to the Forest Service, about three squirrel locations might be lost. Most recently, the US Fish and Wildlife Service has proposed two options, both of which could accommodate the proposed observatory without jeopardizing the continued existence of the red squirrel. Both options permit immediate construction of the $10-\mathrm{m}$ Submillimetre Telescope, the Vatican Advanced Technology Telescope and the 11.3-m Columbus Project and allow for subsequent expansion to seven instruments. Each option would affect two squirrels. In short, the proposed observatory would have a negligible effect on both the squirrel and the general environment. The University of Arizona is therefore confident that the observatory project can and should proceed on what appears to be the best available astronomical site in the continental United States.

More perplexing, amid all the concern for the red squirrel, is the lack of any serious comment on what is threatening its existence. The facts are, however, very clear. In the early 1940 s, the non-native Abert's squirrel was introduced to this sky island site primarily for hunting purposes. It has now taken over all but 2,000 acres of the approximately 30,000 acres of former red squirrel habitat and outnumbers the native squirrel by roughly $20: 1$. It is clear that only one species can survive in the limited habitat provided by Mt Graham. Unless measures are taken, the red squirrel is probably doomed with or without the observatory. As far as we are aware, the UA has made the only specific recovery proposals so far offered. These were contained in its Habitat Conservation Plan proposed under Section 10 of the Endangered Species Act, which permits a proponent to develop and carry out conservation measures in conjunction with a project. These proposals have not been accepted.

In regard to the legislation creating a scientific research area (150 acres) on $\mathrm{Mt}$ Graham, the proposed measure is consistent with US Fish and Wildlife Service and Forest Service recommendations. Indeed, according to the media and other reports, the agencies assisted in preparing draft legislation. Many precedents exist for such action by the US Congress, among them the establishment of the Lowell Observatory in Arizona and Langmuir Laboratories in New Mexico.

The UA is convinced that the proposed Mt Graham scientific research area is necessary for both astronomical and ecological research. It has also convincingly shown that the programme can be carried out without any significant deleterious effects on the environment or any major conflict with other users of the mountain. Indeed, Mt Graham, with its paved access road and public recreational activities, offers excellent opportunities for responsible and productive use.

Peter A. Strittmatter (Director, Steward Observatory) University of Arizona,

Tucson, Arizona 85721, USA

\section{Reductionism}

SIR-John Maddox is quite justified in asserting that the accumulation of data may hinder the successful reduction by molecular biology of biological phenomena, a valid point which Bradbury ${ }^{2}$ has totally neglected to comment upon.

Let us consider the field of mendelian genetics to serve as an example. For years, many scholars have claimed that molecular genetics is the reducing theory of mendelian genetics. Although superficially this seems to be so, the claim is far more complicated than it appears. Before a theory can be said to perform a successful reduction of another, the two criteria of the logical empiricist must be met. First, the general statements of the reduced theory (for our example, mendelian genetics) must follow by deductive logic from the laws of the reducing theory (for our example, molecular genetics). Second, the terms of the reduced theory must be either defined by, or consistently connected, to the terms of the reducing theory. Mendelian genes are defined in terms of their corresponding phenotypes. Mendelian genes therefore have three functions: mutation, expression and recombination ${ }^{3}$. During the 1970 s and 1980s, however, molecular geneticists have extensively (but not exhaustively) researched each of these areas of gene function. Naturally, they have shown conclusively that there are very complex pathways involved in gene expression and recombination. Indeed, a mendelian gene cannot be fully identified with a 'mole- cular gene'. Terms such as intron, exon, promoter, enhancer and suppressor all make impossible a one-to-one correspondence between the two 'genes', and therefore between the two theories. Thus, a many-to-many relationship seems to exist between mendelian and molecular genetics.

Although reduction is still logically possible, it becomes much more difficult to perform. Reductionists are obliged to come to terms with these many-to-many relationships. The most valiant attempt is that by Kenneth Schaffner ${ }^{-1}$. He has corrected mendelian genetics and attempted to reduce the modified version through molecular genetics. Unfortunately, I believe that Schaffner's attempt results in an oversimplification of certain correspondences between the theories.

In short, reduction can occur only if the many-to-many relationship problem is resolved. However, as Maddox correctly points out, this particular task is becoming increasingly difficult as more terms are added to the molecular geneticist's vocabulary. The relationships between the two theories are becoming more complex; therefore, it is becoming more difficult to establish consistent relationships between different terms of each of the theories. Department of the History and Philosophy of Science and Wolfson College,

University of Cambridge,

Cambridge CB3 9BB, UK

Nature 333, 11 (1988)

Vature 333, 794 ( 1988$)$

Rosenberg. A. The Structure of Biological Sciences 95 Cambridge University Press. 1985)

Schaffner. K. in Conceptual Issues in Evolutionary Biology (ed. Sober. E.) (MIT Press. Cambridge. 1984).

\section{Science fellowships}

SIR-Regarding the lower application rate for the fellowships offered by Japan's Science and Technology Agency (Nature 335, 287; 1988). I find it disturbing that Japan's bureaucracy is obsessed with pleasing the politicians of the capitalist Western nations. The stipulation that these fellowships are offered only to the nationals of the United States and ten industrialized countries in Europe and Oceania smacks of parochialism.

If applications for fellowships are considered internationally, disregarding the East-West, North-South labels, I am sure that there will not be any problem in filling the vacancies. Why should not Japan allow a budding Marie Curie from Poland or a cerebral Chen Ning Yang from China to enter its government laboratories?

SACHI. SRI Kantha

Laboratory of Marine Biochemistry,

Faculty of Agriculture,

University of Tokyo,

Bunkyo-ku, Tokyo 113,

Japan 